\title{
The Changing Face of HIV in Pregnancy in Rhode Island 2004-2009
}

\author{
Jacqueline Firth, ${ }^{1,2}$ Chia-Ching Wang, ${ }^{1}$ Fizza Gillani, ${ }^{1}$ Nicole Alexander, ${ }^{1,2}$ \\ Elizabeth Dufort, ${ }^{2}$ Aadia Rana, ${ }^{1}$ and Susan Cu-Uvin ${ }^{3}$ \\ ${ }^{1}$ Department of Medicine, The Warren Alpert Medical School of Brown University, Providence, RI 02912, USA \\ ${ }^{2}$ Department of Pediatrics, The Warren Alpert Medical School of Brown University, Providence, RI 02912, USA \\ ${ }^{3}$ Department of Obstetrics and Gynecology, The Warren Alpert Medical School of Brown University, Providence, \\ RI 02912, USA
}

Correspondence should be addressed to Jacqueline Firth, jacqfirt@gmail.com

Received 20 February 2012; Accepted 20 April 2012

Academic Editor: Deborah Cohan

Copyright () 2012 Jacqueline Firth et al. This is an open access article distributed under the Creative Commons Attribution License, which permits unrestricted use, distribution, and reproduction in any medium, provided the original work is properly cited.

\begin{abstract}
Meeting the needs of HIV-infected pregnant women requires understanding their backgrounds and potential barriers to care and safe pregnancy. Foreign-born women are more likely to have language, educational, and economic barriers to care, but may be even more likely to choose to keep a pregnancy. Data from HIV-infected pregnant women and their children in Rhode Island were analyzed to identify trends in demographics, viral control, terminations, miscarriages, timing of diagnosis, and adherence to followup. Between January 2004 and December 2009, 76 HIV-infected women became pregnant, with a total of 95 pregnancies. Seventy-nine percent of the women knew their HIV status prior to becoming pregnant. Fifty-four percent of the women were foreign-born and 38 percent of the 16 women who chose to terminate their pregnancies were foreign-born. While the number of HIV-infected women becoming pregnant has increased only slightly, the proportion that are foreign-born has been rising, from 41 percent between 2004 and 2005 to 57.5 percent between 2006 and 2009. A growing number of women are having multiple pregnancies after their HIV diagnosis, due to the strength of their desire for childbearing and the perception that HIV is a controllable illness that does not preclude the creation of a family.
\end{abstract}

\section{Introduction}

Understanding and supporting HIV-infected women's awareness of their own status and their options regarding pregnancy requires an understanding of their backgrounds and the potential barriers to care and safe pregnancy. Studies have shown that both social pressures and concerns for vertical transmission play a large role in HIV-infected women's choices about pregnancy [1-3]. Information from around the world supports the fact that since the introduction of reliable methods for the prevention of mother-tochild transmission (PMTCT), fewer HIV-infected women are choosing terminations and many are choosing to become pregnant, even to have multiple pregnancies, after their HIV diagnosis $[2,4-6]$.
Options for safe conception, especially in serodiscordant couples, now include artificial insemination and "sperm washing" [7]. These methods, even where they are available, however, remain relatively unknown and infrequently recommended by many healthcare providers, even in developed countries [8] and may be prohibitively expensive or inaccessible for some couples. In addition to these planned pregnancies, a large number of pregnancies remain unplanned $[9,10]$. Women who live in developing countries, where safer methods of conception are relatively unknown or unavailable, are nevertheless choosing to become pregnant after their HIV diagnosis. A survey of $459 \mathrm{HIV}$-infected men and women in Cape Town, South Africa found that twothirds of women, who became pregnant after commencing highly active antiretroviral therapy (HAART), had intended 
to become pregnant [11]. Furthermore, 50\% of HIV-infected men and women were open to the possibility of conceiving children after their HIV diagnosis; being on HAART had no significant impact on whether or not men intended to pursue pregnancy, but did make women more likely to consider pregnancy [11]. It is unclear what impact moving from a developing to a developed country may have on childbearing intentions, but it is possible that this change in their socioeconomic environment and perceived options for care and support may play a role in women's childbearing intentions.

Women in the USA, who are HIV-infected and foreignborn, may have additional issues to consider during pregnancy. They are more likely to have language, educational, and economic barriers to care and to exercising their options, but may be even more likely to choose to keep a pregnancy because of cultural emphasis on childbearing and negative views of termination. Women who are born in areas of the world where fertility rates are between 5 and 7 children per woman, especially Africa and parts of South and Southeast Asia [12], may experience particular spousal and familial pressure to become pregnant, even if they have disclosed their HIV status [13, 14]. A cross-sectional study done in Canada revealed that $69 \%$ of 490 HIV-infected women desired future pregnancy and African ethnicity was significantly correlated with intention to become pregnant [15].

Although foreign-born persons with HIV living in the US appear to be a growing proportion of the HIV-infected population [16], current national sociodemographic data do not accurately reflect this demographic, as they are generally listed under their ethnicity without distinction about place of birth $[17,18]$. Thus, persons who are originally from SubSaharan Africa, where the highest number of HIV-infected individuals exists, are listed as black/African-American in data used for determining funding and resource allocation. African-born persons often live within their own communities and may not be reached by programs that target AfricanAmericans $[19,20]$. In Washington state, for example, the HIV diagnosis rate among blacks in the state is five times higher than the rate among whites, and $40 \%$ of all HIV diagnoses among blacks in Washington state have been among foreign-born persons [21]. Similar data collected from five different states and high-prevalence areas show that across all areas, up to $41 \%$ of diagnoses in women and up to $50 \%$ of diagnoses in blacks occurred among Africanborn individuals [16]. Additionally, we should not presume all foreign-born persons were necessarily infected with HIV prior to arrival in the USA. Data suggest that in some parts of the country, especially those parts with high numbers of Hispanic immigrants, patients are more likely to have been infected after arrival [22], which may indicate increased vulnerability among foreign-born persons.

Unfortunately, the complex social issues that contribute to women becoming HIV-infected often present barriers to adherence with prescribed medication regimens and prenatal followup, as well as with ensuring adequate testing and followup of the HIV-exposed infant. Studies have shown that $45 \%$ of mothers of HIV-infected infants had missed opportunities for perinatal HIV prevention [23], indicating that although appropriate protocols are in place, additional factors contribute to transmission.

Rhode Island, the smallest state in the United States, had an HIV prevalence of 209 per 100,000 population by the end of 2009 [24]. Among the general population, $81 \%$ of persons identified themselves as White, $12 \%$ identified themselves as Hispanic, and 6\% identified themselves as black or AfricanAmerican [25]. Amongst the 3,080 HIV-infected persons who have been diagnosed in Rhode Island since 1982, 54\% identified themselves as White, $26 \%$ identified themselves as African-American, and $19 \%$ identified themselves as Hispanic [25]. Thus, $45 \%$ of HIV cases in the state have occurred in the $18 \%$ of the population identified as Hispanic or African-American. No data is available on the percentage of HIV-infected persons in the state who are immigrants or foreign-born.

Following the lead of several other states, Rhode Island adopted a law mandating testing of pregnant women during pregnancy or their children immediately after birth. This was done in order to ensure that children receive medication to prevent mother-to-child transmission in a timely manner, and that women are appropriately identified if they need HIV-related services [26]. This law has already led to increased rates of HIV testing during pregnancy, from 52.8\% in 2005-2006 to greater than 95\% after the law changed in 2007 [27], but it is unclear if it has led to an increased number of HIV diagnoses. We seek to describe the experiences of HIV-infected pregnant women and their children followed at a large HIV clinic in Rhode Island.

\section{Materials and Methods}

The Immunology Center at the Miriam Hospital in Providence, Rhode Island, is an urban HIV clinic with 1400 active patients. In 2009, 25\% of HIV patients followed at the Miriam Immunology Center were uninsured or covered only by the hospital's free care program and 32\% were foreign-born. All HIV-infected patients in Rhode Island have access to antiretrovirals either through health insurance or through the Ryan White Program, provided they have been registered as Rhode Island residents. The Immunology Center has been caring for HIV-infected women before, during, and after their pregnancies since its establishment in 1986. The Hasbro Children's Hospital Pediatric Infectious Diseases II Clinic in Providence generally sees all the HIVexposed infants delivered to these women. These clinics follow DHHS guidelines for perinatal prevention of motherto-child transmission and follow-up testing for HIV-exposed infants. The two clinics are the largest providers for HIVinfected women and their children in Rhode Island. This study aims to characterize and understand the recent trends in the HIV-infected pregnant population and HIV-exposed children in Rhode Island.

Social and clinical data from HIV-infected pregnant women collected regularly by the Immunology Center staff for care and research purposes were analyzed to identify and characterize trends in demographics, viral control, terminations, miscarriages, timing of diagnosis, 
and adherence to followup. Data on the adherence with follow-up appointments and testing for the HIV-exposed infants were obtained from paper and online charts from both Hasbro Children's Hospital's primary care clinics and Pediatric Infectious Diseases II Clinic. Data were analyzed for means of continuous variables (viral load, CD4 counts, etc.), percentages of descriptive variables (US-born versus foreignborn, outcome of pregnancy, mode of delivery, etc.) and significant correlations between variables using Statistical Package for the Social Sciences (SPSS) Version 17.0 (Chicago, IL, USA). Statistical significance was assessed using a chisquare test. This project was reviewed and approved by the Miriam and Rhode Island Hospital (including Hasbro Children's Hospital) Institutional Review Boards.

\section{Results}

Between January 2004 and December 2009, 321 HIVinfected women between 18 and 45 years old were seen at the Immunology Center. Seventy-six HIV-infected women became pregnant, with a total of 95 pregnancies. Seventeen women had more than one pregnancy, and two women had three pregnancies. Fifty-five percent of these women were foreign-born. Sixteen of the women (21\%) were diagnosed with HIV during their pregnancy while $79 \%$ knew their HIV status prior to becoming pregnant. Sixteen of the women chose to terminate their pregnancies $(17 \%$ of total pregnancies in this cohort); two of these women were diagnosed during this pregnancy and both were US-born. Seven women suffered miscarriages. The trends by year and breakdown of specifics between foreign-born and US-born women are presented in Tables 1 and 2. The breakdown by continent/region of origin of the women is shown in Figure 1. Among the thirty women from Africa, sixteen were from Liberia, three from Burundi, two from Guinea, Kenya, and Senegal and one each from Angola, Ghana, Ivory Coast, Mali, and Sierra Leone. Among the seven women from Latin America, there were three women from the Dominican Republic, two from Guatemala, and one each from Venezuela and Argentina.

While the number of HIV-infected women becoming pregnant increased only slightly over the years of the study, the proportion of women that were foreign-born rose from $41 \%$ between 2004 and 2005 to $57.5 \%$ between 2006 and 2009. There was no significant difference between USborn and foreign-born women in terms of their likelihood of being diagnosed with HIV during pregnancy, choosing termination or choosing to have a second or third pregnancy. US-born women were more likely to have fewer than two visits during the pregnancy or Department of Children, Youth \& Families (DCYF) involvement with their children.

Of the 72 women who had pregnancies that did not end in miscarriage or termination, mode of delivery was known for 49 . Seventeen $(35 \%)$ delivered vaginally, twenty-five (51\%) underwent elective caesarian section, and seven (14\%) required emergency caesarian sections. Sixty-three women had CD4 counts and plasma viral loads (PVL) measured during pregnancy. Fifteen (24\%) women had detectable plasma viral loads on their last test prior to delivery, and all but one of them underwent caesarian section (information on the mode of delivery for one woman is missing). Thirty women had both information on viral load prior to delivery and mode of delivery available. Of these, sixteen (53\%) had undetectable viral loads and six (20\%) had viral loads less than 1000. Only eight of the women who underwent caesarian section had viral loads above 1000, and five of these women had either repeat caesarian section or underwent the procedure due to emergency indications unrelated to viral load. Nine women were considered to have AIDS at the time of delivery, based on a last CD4 count prior to delivery less than 200 cells $/ \mu \mathrm{L}$. Seven of these women were foreign-born. The mean CD 4 count prior to delivery was 480 cells $/ \mu \mathrm{L}$.

Three children in this cohort were confirmed to be perinatally-infected. All of them were born to mothers with psychological and/or social issues that had a significant impact on their ability to adhere to appropriate followup and preventive measures. One mother was a young perinatallyinfected teenager at the time of her first pregnancy. She received care in both Rhode Island and Massachusetts, but was unable to adhere adequately to care and treatment at either site. The second child was born to a woman from West Africa who had been diagnosed with HIV three years before the pregnancy upon immigration to the USA. She did not adhere to her medication regimen during pregnancy and DCYF was involved soon after the child was born. The third child was born to a US-born woman who had been diagnosed with HIV during a prior pregnancy. She had delivered an HIV-negative child at that time, who was subsequently removed from her custody. She had been out of care and off HIV medications for many months when she presented to the emergency department with complaint of abdominal pain. She was quickly determined to be in active labor. She denied knowing that she had been pregnant and had received no prenatal care.

\section{Discussion}

As has been seen around the world, our data suggest that HIV-infected women are increasingly choosing to become pregnant and to keep pregnancies that may have been unplanned. The number of terminations has remained low. This is consistent with other studies that have shown that fewer HIV-infected women are choosing termination now that the efficacy of methods for prevention of motherto-child transmission (PTMCT) are well-known and wellvalidated $[2,4-6]$. Additionally, a growing number of women are having second and even third pregnancies after their HIV diagnosis. This trend likely reflects both the strength of the desire to have children and the perception of HIV as a controllable illness that does not preclude the creation of a family.

Our data indicate that Rhode Island's relatively new optout law for HIV testing among pregnant women, and the resultant increased rate of testing, has not resulted in a higher number of HIV diagnoses; however, its effects may not yet be reflected in our data as this law was only passed in July 2007. In addition, Rhode Island is known to have a low prevalence of HIV, and the increased testing may 


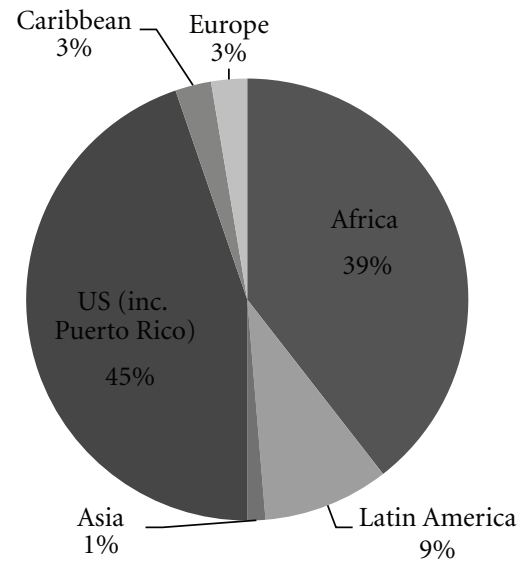

FIGURE 1: Continent/region of origin among HIV-infected pregnant women in RI.

TABLE 1: Trends in pregnancies among HIV-infected women followed by the Immunology Center.

\begin{tabular}{|c|c|c|c|c|c|c|}
\hline Year & $\begin{array}{c}\text { Number of pregnant } \\
\text { HIV+ women }\end{array}$ & $\begin{array}{c}\text { Women in } 2 \mathrm{nd} / 3 \mathrm{rd} \\
\text { pregnancy }\end{array}$ & $\begin{array}{c}\text { Percent foreign-born } \\
\text { women }\end{array}$ & $\begin{array}{c}\text { Number of } \\
\text { terminations }\end{array}$ & $\begin{array}{l}\text { Number of } \\
\text { miscarriages }\end{array}$ & $\begin{array}{l}\text { Number diagnosed } \\
\text { HIV+ in pregnancy }\end{array}$ \\
\hline 2004 & 10 & 0 & $40 \%$ & 1 & 0 & 4 \\
\hline 2005 & 12 & 0 & $42 \%$ & 4 & 2 & 0 \\
\hline 2006 & 21 & 2 & $62 \%$ & 4 & 2 & 3 \\
\hline 2007 & 21 & 10 & $52 \%$ & 5 & 2 & 3 \\
\hline 2008 & 15 & 5 & $60 \%$ & 2 & 0 & 1 \\
\hline 2009 & 16 & 4 & $56 \%$ & 0 & 1 & 5 \\
\hline Total & 95 & 21 & $54 \%$ & 16 & 7 & 16 \\
\hline
\end{tabular}

not result in a significantly higher number of diagnoses. Furthermore, laws to encourage testing during physician encounters outside of pregnancy may negate any potential increase in diagnoses during pregnancy.

While the number of HIV-infected women becoming pregnant in our clinic has increased only slightly, the proportion that are foreign-born has been steadily rising, from an average of $41 \%$ between 2004 and 2005 to $57.5 \%$ between 2006 and 2009. Now that the Obama administration has lifted the travel ban on HIV-infected persons entering the USA (as of January 2010), this trend may increase as the number of foreign-born HIV-infected women entering the USA continues to grow. However, the numbers seen in Rhode Island may also decline, as the freedom to enter any state may lead to some choosing to settle elsewhere. Previously, Rhode Island was one of the few states that was allowed to accept $\mathrm{HIV}$-infected individuals emigrating to the USA under the travel ban.

Available virologic control data for our clinic indicate that most women have favorable CD4 counts and undetectable viral loads prior to delivery. All the women who had detectable viral loads underwent caesarian section, which is associated with a lower risk of viral transmission for women with HIV plasma viral loads $>1000$ copies/mL near the time of delivery. The three cases of perinatal transmission are not necessarily representative of the overall outcomes of pregnancy among HIV-infected women. However, they are indicative of the fact that while PMTCT protocols are now able to reduce the risk of HIV transmission to less than $2 \%$, they cannot do so if patients are unable to adhere to them. In our small state, during the time period of this study, there was essentially one clinic and one HIV-trained obstetrician/gynecologist who saw the women during pregnancy, one hospital where they delivered, and one pediatric infectious disease clinic where the children were followed. Each of these settings has robust medical, social work and support staff that fully supported each HIV-infected pregnant woman in order to optimize her care and adherence to therapy. These data highlight the fact that despite this level of coordination and support, nonadherence does occur and perinatal HIV transmission may ensue. Further study to identify "at-risk" women may be warranted, in order to target further medical and psychosocial interventions in order to improve outcomes and decrease maternal-to-child transmission.

These study results support prior trends noted from US and international studies that HIV-infected women are increasingly choosing to become pregnant or to continue a pregnancy. Studies are needed to determine the knowledge and attitudes of foreign-born and US-born HIV-infected women regarding childbearing and prevention of maternalto-child transmission. Additionally, comparative studies among women in high HIV-prevalence regions and women who have moved from those regions to resource-rich settings would help healthcare providers and systems to anticipate and meet the needs of a growing population of HIV-infected 
TABle 2: Pregnancy outcomes among foreign-born versus US-born women.

\begin{tabular}{|c|c|c|c|c|}
\hline & $\begin{array}{l}\text { Foreign-born HIV-infected women } \\
\qquad n=150\end{array}$ & $\begin{array}{l}\text { US-born HIV-infected women } \\
n=149\end{array}$ & $\begin{array}{c}\text { Total } \\
n=321\end{array}$ & $P$ value \\
\hline Number of pregnancies & 51 & 44 & 95 & 0.41 \\
\hline $\begin{array}{l}\text { Number diagnosed during pregnancy } \\
\text { ( } n=76 \text { women })\end{array}$ & 8 & 8 & $16(21 \%)$ & 0.75 \\
\hline Number of terminations & 6 & 10 & $16(17 \%)$ & 0.154 \\
\hline Number of miscarriages & 3 & 4 & $7(7 \%)$ & 0.55 \\
\hline $\begin{array}{l}\text { Number of C-sections (of those with } \\
\text { known mode of delivery) }\end{array}$ & $20 / 29$ & $12 / 20$ & $32 / 49(65 \%)$ & 0.51 \\
\hline Number of 2nd and 3rd pregnancies & 10 & 11 & $21(22 \%)$ & 0.53 \\
\hline $\begin{array}{l}\text { Number with undetectable viral load } \\
\text { prior to delivery (of those with test data } \\
\text { available) }\end{array}$ & $32 / 38$ & $16 / 25$ & $48 / 63(76 \%)$ & 0.065 \\
\hline 2 or more clinic visits during pregnancy & 36 & 22 & $58(61 \%)$ & 0.04 \\
\hline DCYF involvement & 4 & 12 & $16(17 \%)$ & 0.012 \\
\hline
\end{tabular}

*Of the 321 women between 18-45 years seen from 1/04 to 12/09, place of birth is unknown for 22 .

DCYF $=$ Department of Children, Youth \& Families.

women who may have different understandings of, and barriers to, exercising options for safe pregnancy.

\section{Conclusion}

The face of HIV in pregnancy is changing. HIV-infected women in Rhode Island are more likely to be foreign-born, to know their HIV status prior to pregnancy, and to actively choose to become pregnant or to continue pregnancies, whether planned or unplanned. Despite increasing rates of HIV testing in pregnancy, an increased number of HIV diagnoses has not been seen. When HIV-infected pregnant women engage with appropriate prenatal care, virologic control is generally excellent and outcomes are good for mother and child. However, risks for HIV transmission beyond lack of awareness of HIV status are emerging, especially among women with psychological or social issues, which may preclude adherence to PMTCT protocols and lead to unnecessary infection of infants. Foreign-born women are a growing percentage of the population of HIV-infected women becoming pregnant in the USA and may benefit from further study and targeted interventions. Identifying "at-risk" women during their pregnancy and providing extra social, psychological, and other support to them may be an important additional focus for PMTCT programs in order to continue to prevent perinatal HIV transmission.

\section{Acknowledgments}

This study was supported by funds from the Lifespan/ Tufts/Brown University Center for AIDS Research NIH P30AI42853 and Dr. S. Cu-Uvin was supported by NIH K24AI066884.

\section{References}

[1] B. Nattabi, J. Li, S. C. Thompson, C. G. Orach, and J. Earnest, "A systematic review of factors influencing fertility desires and intentions among people living with HIV/AIDS: implications for policy and service delivery," AIDS and Behavior, vol. 13, no. 5, pp. 949-968, 2009.

[2] S. B. Kirshenbaum, A. E. Hirky, J. Correale et al., "“Throwing the dice": pregnancy decision-making among HIV-positive women in four U.S. cities," Perspectives on Sexual and Reproductive Health, vol. 36, no. 3, pp. 106-113, 2004.

[3] B. H. B. Van Benthem, I. De Vincenzi, M. C. Delmas, C. Larsen, A. Van Den Hoek, and M. Prins, "Pregnancies before and after HIV diagnosis in a European cohort of HIV-infected women," AIDS, vol. 14, no. 14, pp. 2171-2178, 2000.

[4] S. K. Whitmore, X. Zhang, A. W. Taylor, and J. M. Blair, "Estimated number of infants born to HIV-infected women in the United States and five dependent areas, 2006," Journal of Acquired Immune Deficiency Syndromes, vol. 57, no. 3, pp. 218-222, 2011.

[5] A. S. Bryant, R. M. Leighty, X. Shen et al., "Predictors of repeat pregnancy among HIV-1-infected women," Journal of Acquired Immune Deficiency Syndromes, vol. 44, no. 1, pp. 8792, 2007.

[6] A. Sharma, J. G. Feldman, E. T. Golub et al., "Live birth patterns among human immunodeficiency virus-infected women before and after the availability of highly active antiretroviral therapy," American Journal of Obstetrics and Gynecology, vol. 196, no. 6, pp. 541.e1-541.e6, 2007.

[7] L. Bujan, L. Hollander, M. Coudert et al., "Safety and efficacy of sperm washing in HIV-1-serodiscordant couples where the male is infected: results from the European CREAThE network," AIDS, vol. 21, no. 14, pp. 1909-1914, 2007.

[8] T. Newmeyer, S. N. Tecimer, D. Jaworsky et al., "Case series of fertility treatment in HIV-discordant couples (male positive, female negative): the Ontario experience," PLoS One, vol. 6, no. 9, Article ID e24853, 2011.

[9] M. R. Loutfy, J. M. Raboud, J. Wong et al., "High prevalence of unintended pregnancies in HIV-positive women of reproductive age in Ontario, Canada: a retrospective study," HIV Medicine, vol. 13, no. 2, pp. 107-117, 2012.

[10] P. J. Orner, M. De Bruyn, R. M. Barbosa, H. Boonstra, J. GatsiMallet, and D. D. Cooper, "Access to safe abortion: building choices for women living with HIV and AIDS," Journal of the International AIDS Society, vol. 14, no. 1, Article ID 54, 2011. 
[11] D. Cooper, J. Moodley, V. Zweigenthal, L. G. Bekker, I. Shah, and L. Myer, "Fertility intentions and reproductive health care needs of people living with HIV in Cape Town, South Africa: implications for integrating reproductive health and HIV Care services," AIDS and Behavior, vol. 13, no. 1, pp. S38-S46, 2009.

[12] Central Intelligence Agency, US Government, "Country comparison: total fertility rate," https://www.cia.gov/library/ publications/the-world-factbook/rankorder/2127rank.html.

[13] N. Suryavanshi, A. Erande, H. Pisal et al., "Repeated pregnancy among women with known HIV status in Pune, India," AIDS Care, vol. 20, no. 9, pp. 1111-1118, 2008.

[14] B. K. Chi, V. Rasch, N. Thi Thúy Hanh, and T. Gammeltoft, "Pregnancy decision-making among HIV positive women in Northern Vietnam: reconsidering reproductive choice," Anthropology \& Medicine, vol. 18, no. 3, pp. 315-326, 2011.

[15] M. R. Loutfy, T. A. Hart, S. S. Mohammed et al., "Fertility desires and intentions of HIV-positive women of reproductive age in Ontario, Canada: a cross-sectional study," PloS one, vol. 4, no. 12, p. e7925, 2009.

[16] J. R. Castillo-Mancilla and M. Carten, "The need for a US registry of HIV in foreign-born people," The Lancet Infectious Diseases, vol. 10, no. 6, pp. 370-371, 2010.

[17] Centers for Disease Control and Prevention (CDC), "Racial/ethnic disparities in diagnoses of HIV/AIDS-33 states, 2001-2004," Morbidity and Mortality Weekly Report, vol. 55, no. 5, pp. 121-125, 2006.

[18] Centers for Disease Control and Prevention (CDC), "Racial/ethnic disparities among children with diagnoses of perinatal HIV infection-34 states, 2004-2007," Morbidity and Mortality Weekly Report, vol. 59, no. 4, pp. 97-101, 2010.

[19] R. P. Kerani, J. B. Kent, T. Sides et al., "HIV among Africanborn persons in the United States: a hidden epidemic?" Journal of Acquired Immune Deficiency Syndromes, vol. 49, no. 1, pp. 102-106, 2008.

[20] E. E. Foley, "HIV/AIDS and African immigrant women in Philadelphia: structural and cultural barriers to care," AIDS Care, vol. 17, no. 8, pp. 1030-1043, 2005.

[21] J. B. Kent, "Impact of foreign-born persons on HIV diagnosis rates among Blacks in King County, Washington," AIDS Education and Prevention, vol. 17, pp. 60-67, 2005.

[22] N. T. Harawa, T. A. Bingham, S. D. Cochran, S. Greenland, and W. E. Cunningham, "HIV prevalence among foreign- and USborn clients of public STD clinics," American Journal of Public Health, vol. 92, no. 12, pp. 1958-1963, 2002.

[23] V. B. Peters, K. L. Liu, L. G. Robinson et al., "Trends in perinatal HIV prevention in New York City, 1994-2003," American Journal of Public Health, vol. 98, no. 10, pp. 18571864, 2008.

[24] Centers for Disease Control and Prevention (CDC), "Rates of adults and adolescents living with a diagnosis of HIV infection, year-end 2009-46 states and 5 U.S. Dependent Areas," http://www.thebody.com/content/art59071.html.

[25] Rhode Island Department of Health Division of Community Family Health and Equity, Office of HIV/AIDS \& Viral Hepatitis, "2010 Rhode Island HIV/AIDS Epidemiologic Profile with Surrogate Data," September 2011, http://www.health .ri.gov/publications/epidemiologicalprofiles/2010HIVAIDSWithSurrogateData.pdf.

[26] Rhode Island Department of Health, "HIV testing in pregnancy," http://www.health.ri.gov/publications/factsheets/HIVTestingInPreganancy.pdf.
[27] N. E. Alexander, B. Alverson, R. Neale, and C. G. Beckwith, "The implementation of the CDC's revised recommendations for HIV testing in medical settings: a Rhode Island update and call for action," Medicine and Health, Rhode Island, vol. 92, no. 7, pp. 247-248, 2009. 


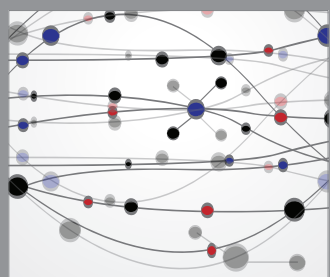

The Scientific World Journal
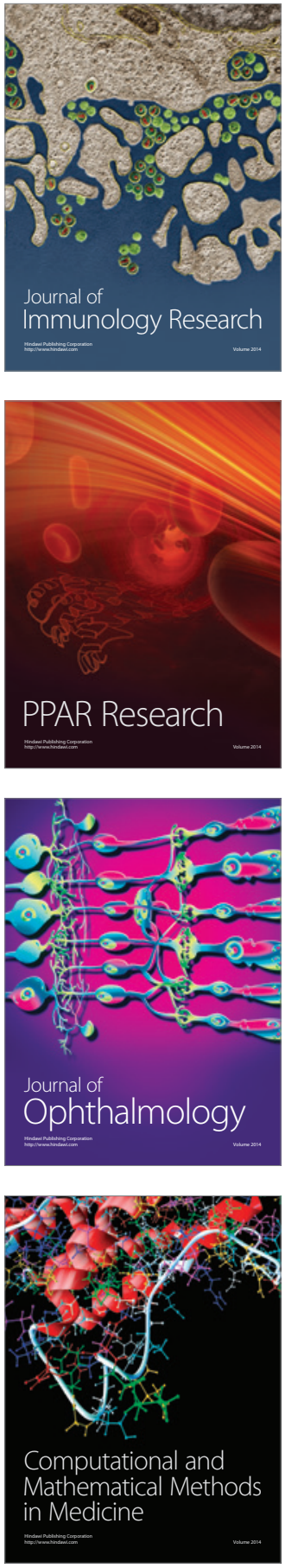

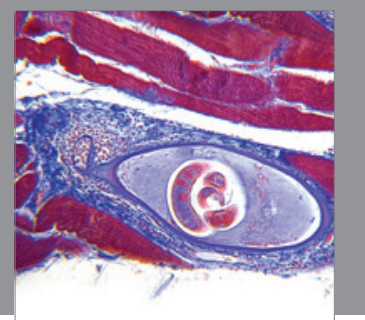

Gastroenterology

Research and Practice
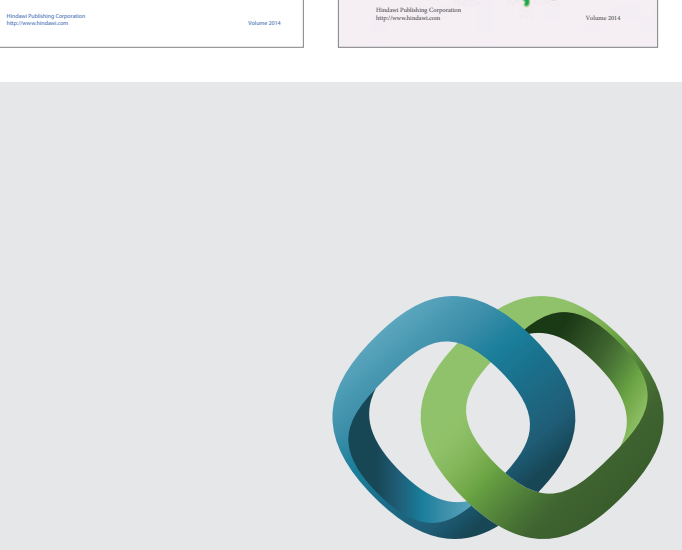

\section{Hindawi}

Submit your manuscripts at

http://www.hindawi.com
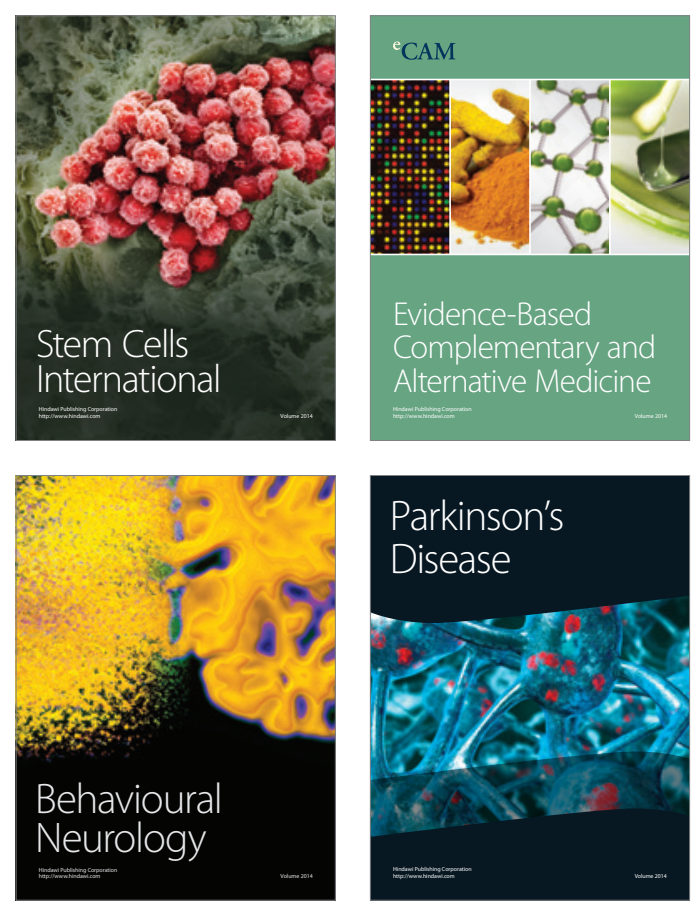

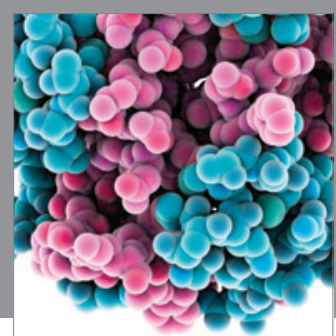

Journal of
Diabetes Research

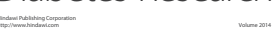

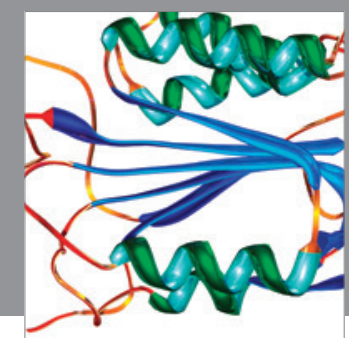

Disease Markers
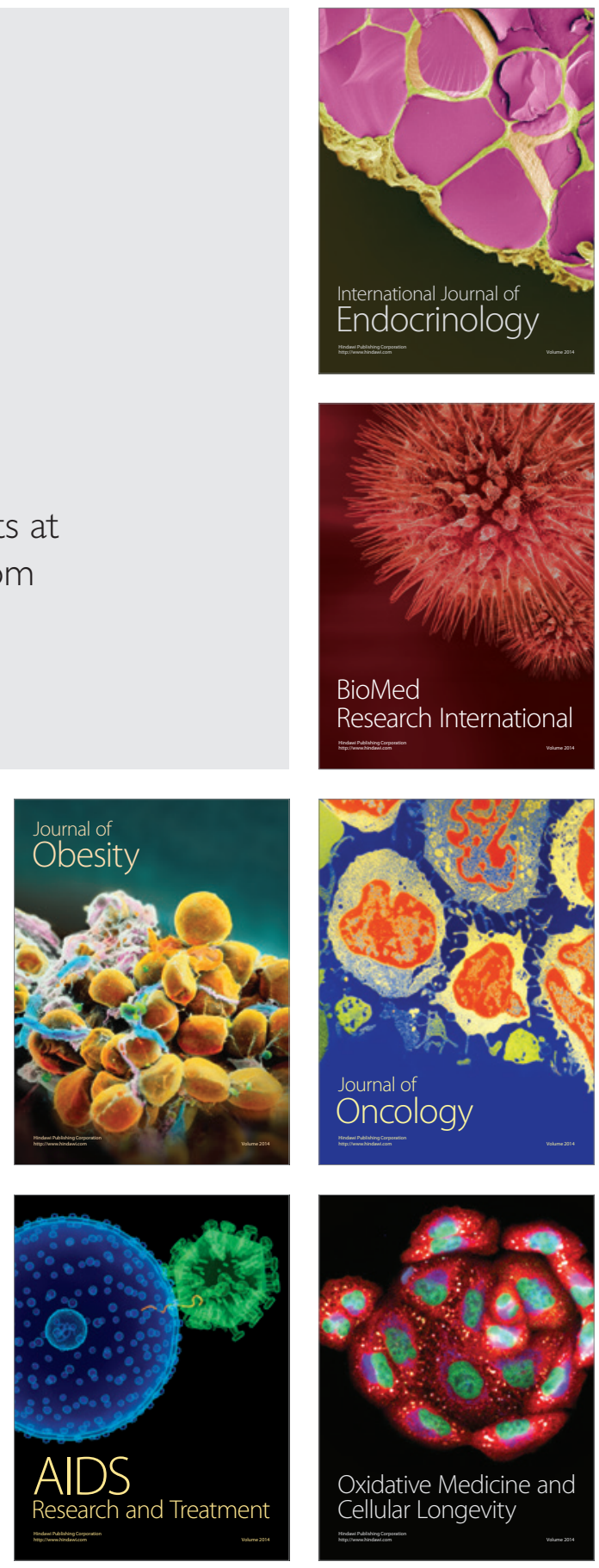